restricted to the western half, while a few afford examples of discontinuity, particularly the swamp species Leitneria floridana found as a native tree in Florida and again from Missouri to Texas. The few species confined to the western States comprise two conifers and two poplars.

Keys are provided to the genera and species, although as these depend in large part on reproductive characters their usefulness is limited. The text and illustrations of this work together constitute a valuable and convenient source of information that will be of service alike to the botanist, the arboriculturist and the forester.

"Trees for Town and Country" is a book of a more utilitarian character in which the emphasis is naturally placed upon growth and habit rather than on details of morphology. Each of the sixty species selected is illustrated by a full-page photograph. Many of these are excellent both as typifying the species portrayed and as tree portraits; but a few scarcely do justice to their subjects, as, for example, those of Catalpa speciosa, Prunus avium and Carpinus betulus, and, particularly with respect to the lastnamed, fail to convey their potentialities. The hornbeam is a really superb tree when allowed to develop properly, although this is too little realized because its tolerance of trimming and pollarding has so often destroyed its intrinsic merits both in winter and summer.

Each photograph is accompanied by line drawings by S. R. Badmin which are both useful and charming, representing, as they do, the details of structure, the winter appearance and the average heights of the species at various ages, so that the prospective planter can judge the space required and the probable effect on the Jandscape. The figures are accompanied by short notes on soil, climate, growth and cultural details.

For the tyre especially, this work should prove a very real aid in assessing the merits of the more familiar subjects; though it must be borne in mind that such selections as this suffer from the defects of their merite and may, unless used with caution, lead to stereotyped planting and failure to utilize species such as, for example, Prunus padus, Tilia parvifolia, Tilia petiolaris, and Sorbus torminalis, which though not included here, may, in certain cireumstances, have a prior claim to consideration.

E. J. SAIISBURY

\section{BRAIN AND MIND}

\section{The Physical Background of Perception}

By E. D. Adrian. (Being the Waynflete Lectures delivered in the College of St. Mary Magdalen, Oxford, in Hilary Term 1946.) Pp. viii + 95. (Oxford: Clarendon Press ; London : Oxford University Press, 1947.) 10s. net.

DHYsiology has been defined as the outcome Pof a curiosity about ourselves. Such curiosity reaches its peak in the attempt to discover what material events in the brain accompany, and might be responsible for, the conscious processes of feeling and thought. The brain-mind relation is the noman's-land on which the theologian, the psychologist and the physiologist meet face to face. The problem is age-old, and no immediate solution is in sight. The physiological approach has, however, advanced somewhat in recent years. This has been chiefly due to the work of Prof. E. D. Adrian at Cambridge, who summarized the present position in his Waynflete Lectures at Magdalen College, Oxford, in 1946, which are now available.

Prof. Adrian starts from the point that what goes on in the brain is to a large extent determined by what comes into it from the sense organs. It is firmly established that only one type of nervous message, the standard nerve impulse, is transmitted in the nervous system. There is thus only one common form of signalling available, and the message sig. nalled depends for its qualitative interpretation on where it has come from and where it arrives. The sense organs sensitive to one particular type of physical or chemical change are connected by their own private pathway to one particular part of the cerebral cortex, which constitutes the cortical area in which that particular sensation is perceived. Within each cortical area there is a spatial localization of the different parts of the peripheral sensory field. The cortex may thus be regarded as a sensitive screen on which is projected a map or replica of the external world as appreciated by the sense organs.

This cortical projection of sensory data is a concrete reality; it is a pattern of electrical activity which can be mapped out in considerable detail by physiological methods. The map has been fully studied in anæsthetized animals, and the main conclusions have been confirmed in man during surgical operations on the brain. There is no direct proof that the intensity and duration of a sensation are strictly related to the temporal pattern of nerve impulses arriving at the cortex, but the accumulation of much indirect evidence makes this highly probable. One important point, which Adrian's work has clearly brought out, is that the size of the cortical area allocated to a particular sensation coming from a particular part of the body is not determined by the size of the sensory field concerned but rather by the importance which that particular part of sensation has for the conscious behaviour response of the animal. Naturally this varies considerably in different species. In the pig, for example, the tactile area for the snout is quite disproportionately large as com. pared with that for the rest of the body and with other species. In man, the tactile area for the hand is much bigger than that for the foot.

- The arrival of sensory impulses in the cortex can be studied in the anæsthetized animal; but the next stage, the inquiry into what happens in the brain after the impulses arrive, and the relation of this to mental processes, must be pursued in conscious man. Here the technical difficulty that electrical recording can, ordinarily, only be carried out through the thickness of the skull precludes any very exact localization. Nevertheless, one very import. ant and unexpected discovery has been made. When the cortex is inactive, as during anæsthesia, in sleep or simply during inattention, there is a synchronous rhythmical activity of the cortical cells at a frequency of 7-10 impulses per second ( $\alpha$-rhythm). This rhythm originates in the parieto-occipital area, but extends over the greater part of the cortex. When conscious attention is given to what is seen, or when mental calculations are performed, the rhythm disappears or is replaced by a faster local rhythm. The transference of conscious attention to one particular area of the cortex appears to involve the setting free of hat area from the basic $\alpha-r h y t h m$ so that it can be used by the 'mind'. The only prerequisite for the existence 
of consciousness seems to be that some part of the cortex, and not necessarily a large part, should be freed from the $\alpha$-rhythm and so made receptive to incoming sensory messages. The mechanism which suppresses the natural $\alpha$-rhythm and so causes, or allows, consciousness, does not reside in the cortex itself; it appears to originate in the upper part of the brain stem and almost certainly involves the hypothalamus.

So far a mechanistic interpretation suffices; but when we inquire how the brain recognizes and remembers things, very serious difficulties arise. For example, we know that a tune is recognized whatever its key, and a shape is recognized whatever its size and whatever part of the retina its image falls on. So it is obviously not a precise stimulation of certain nerve cells which the cortex recognizes; it must be some abstract pattern or concept which the brain in some way distils from actual sensory data and stores in its memory. Similarly, on the motor side, once a complex skilled movement has been learnt, it can be carried out, though less perfectly, with quite different muscles. Recognition and habit formation cannot, therefore, be due to the facilitation of particular nerve pathways by repeated use. On the sensory side, there must be something which abstracts the significant elements of a pattern; and on the motor side, something which converts an abstract idea of movement into an actual movement.

It is just here that all mechanistic hypotheses seem to break down, and it is in this that the brain differs from all man-made contrivances such as gun predictors, mine detonators and calculating machines. These machines respond when a certain fixed pattern of stimulation reaches a certain threshold. The brain, on the other hand, responds to an abstract pattern and is not tied to a critical threshold of stimulation. Indeed, the property of adaptation, so characteristic of the nervous system, renders it singularly inefficient in the recognition of absolute intensities of stimulation; it can only be relied upon to compare one thing with another.

This is the fundamental problem which confronts those who seek to explain mental processes in physiological terms. Adrian himself can see no immediate prospect of its solution, but he directs attention to certain ideas of Lashley and of Craik which might afford an approach. He concludes that, as contemporary physiology is unable to give a satisfactory account of any kind of mental activity, there is, as yet, no risk of its incursion into the field of metaphysics.

O. A. Troweld

\section{MEDICAL DISEASES IN HOT CLIMATES}

\section{Memoranda on Medical Diseases in Tropical and Sub-Tropical Areas. (War Office)}

Eighth edition. Pp. 396 (37 plates). (London : H.M. Stationery Office, 1946.) 7s. 6d. net.

\footnotetext{
A $S$ vast numbers of troops were engaged in campaigns in the Pacific, South-East Asia and the Middle East, it is not surprising that many advances in medical knowledge of tropical diseases were made during the last four vital years of the Second World War. Much of this new knowledge is included in the present publication.
}

The book comprises thirty-nine memoranda arranged in alphabetical order. New articles are included on nutritional diseases, infective hepatitis, tropical eosinophilia, leprosy and the sulphonamides.

The section on arthropod pests contains pertinent information on the various uses of D.D.T. in the control of both the wingless and winged pests. Its special value in the destruction of mosquito larvæ and adult anophelines, house flies and lice is emphasized. D.D.T., however, was ineffective in preventing scrub typhus, and here dibutyl-phthalate applied to clothing proved the repellent of choice, as it afforded most effective protection against the larval mite vector.

An instructive account is given of infective hepatitis based on the 'Alamein Line' outbreak affecting 10,000 troops. This is followed by a consideration of arsenical and homologous serum jaundice--both of which resemble in many respects infective hepatitis. The view is accepted that both these conditions are caused by inoculation with blood or serum containing a virus or some allied icterogenic agent. The comprehensive account on cysticercosis is abridged from the classical work of MacArthur on this subject; it is now gratifying to read that the more recent followup of Dixon and Hargreaves shows the prognosis to be brighter than was at first supposed.

The view that secondary invading organisms play an important part in those chronic cases of amœbiasis which prove intractable to amœbicidal drugs is accepted; preliminary treatment with sulphonamides and penicillin is advocated in such circumstances.

As a result of field experience with bacillary dysentery, it is advised that all individuals developing diarrhoa should be immediately treated with sulphaguanidine. This procedure not only reduced hospitalization by preventing the development of clinical dysentery, but also eliminated carriers and cut short epidemics through destruction of dysentery baclli in the stools.

In the chapter on malaria, some twenty-four out of thirty-six pages are devoted to treatment. Doubt is expressed whether intramuscular 'Mepacrine' can replace intravenous quinine in the urgent treatment of cerebral and algid malaria. The great value of 'Mepacrine' as a suppressive in a dosage of $0.1 \mathrm{gm}$. daily is emphasized, resulting, as it does, in the radical cure of malignant tertian malaria and the suppression of benign tertian infections. The statement is made that "its use in the 1939-1945 war gave us great tactical advantages against the Japanese-we could operate in malarious areas which they had to avoid". While the first part of this statement is undoubtedly correct, it is doubtful if the Japanese ever considered the military implications of malaria or of any other disease in their forward planning.

A valuable addition to future editions would be the inclusion of graphs based on statistical data showing the dramatic reduction in the incidence of diseases like malaria, bacillary dysentery and scrub typhus following the introduction of preventive measures and chemotherapeutic control during the later pbases of the Pacific and Burma campaigns.

As stated in the preface, the aim of this book is to give medical officers something that can be more easily carried about than a text-book and yet offer in a concise form the essentials of the more important diseases of the tropies. This objective has been splendidly achieved in the eighth edition.

\section{N. Hamilton FaIRLey}

